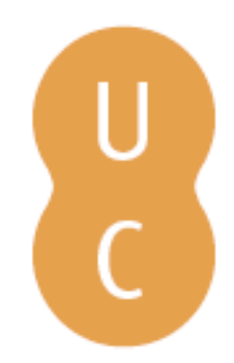

\title{
nombalina
}

Olimpismo e exaltação da individualidade: das origens aos jogos contemporâneos

Autor(es): Sobral, Francisco

Publicado por: Imprensa da Universidade de Coimbra

URL

persistente: URI:http://hdl.handle.net/10316.2/38377

DOI: $\quad$ DOI:http://dx.doi.org/10.14195/978-989-26-0371-1_15

Accessed : $\quad$ 26-Apr-2023 10:27:26

A navegação consulta e descarregamento dos títulos inseridos nas Bibliotecas Digitais UC Digitalis, UC Pombalina e UC Impactum, pressupõem a aceitação plena e sem reservas dos Termos e Condições de Uso destas Bibliotecas Digitais, disponíveis em https://digitalis.uc.pt/pt-pt/termos.

Conforme exposto nos referidos Termos e Condições de Uso, o descarregamento de títulos de acesso restrito requer uma licença válida de autorização devendo o utilizador aceder ao(s) documento(s) a partir de um endereço de IP da instituição detentora da supramencionada licença.

Ao utilizador é apenas permitido o descarregamento para uso pessoal, pelo que o emprego do(s) título(s) descarregado(s) para outro fim, designadamente comercial, carece de autorização do respetivo autor ou editor da obra.

Na medida em que todas as obras da UC Digitalis se encontram protegidas pelo Código do Direito de Autor e Direitos Conexos e demais legislação aplicável, toda a cópia, parcial ou total, deste documento, nos casos em que é legalmente admitida, deverá conter ou fazer-se acompanhar por este aviso.

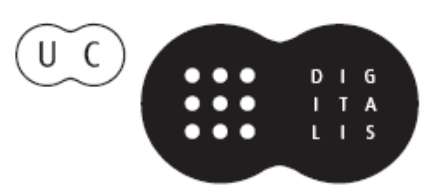


FRANCISCO DE OLIVEIRA

Coordenação

Ospírito Olímpico

no

novo milénio 


\section{OLIMPISMO E EXALTAÇÃO DA INDIVIDUALIDADE: DAS ORIGENS AOS JOGOS CONTEMPORÂNEOS}

Francisco So bral Universidade de Coimbra

Como explicar que, na iconografia desportiva, as figuras proeminentes, com lenda tecida à sua volta nos últimos cem anos, sejam, na sua grande maioria, atletas de desportos individuais? Paavo Nurmi, Johnny Weissmuller, Sonja Heine, Emil Zatopek, Roger Bannister, Fausto Coppi, para citar apenas alguns dos mais antigos. Mesmo ao cidadão de interesses mais afastados do fenómeno desportivo são familiares nomes de grandes atletas que os media entronizam na galeria dos heróis populares.

Que valores e representações justificam que, em todas as recentes votações para eleger o Atleta do Século, a escolha tenha recaído em figuras desses chamados "desportos individuais"? E por que razão, chamados a eleger a figura mais notável entre os desportistas, jurados e público em geral concordaram na atribuição do título a um pugilista, um nadador ou um campeão de atletismo - ou, pelo menos, aceitaram pacificamente esse desfecho?

Como entender que, sendo o futebol, numa extensa parte do mundo, o desporto que agarra a atenção das maiores multidões e, pela sua mediatização, aquele que mais promove os seus ícones, os futebolistas apareçam em plano secundário quer nas nomeações quer nas classificações finais atribuídas?

Este sentido de escolha verifica-se, de resto, não apenas em relação ao futebol mas também a outras modalidades de equipa que, em alguns países, gozam de preferência pública semelhante. Nos Estados Unidos, 
por exemplo, onde Michael Jordan, do basquetebol, ou Joe Montana, do futebol americano, são heróis entronizados na admiração popular, as escolhas repartiram-se entre Muhammad Ali e Cari Lewis, com algumas incursões avulsas pelo meio, como foi o caso do nadador Mark Spitz. A tendência parece ter, assim, carácter universal. São verosímeis algumas excepções - para jogadores de críquete, por exemplo, dos pequenos países das índias Ocidentais - entre outras hipóteses pitorescas mas confinadas a um contexto geográfico muito restrito.

Mais importante do que julgar sobre o acerto dos eleitores é procurar entender o significado desta inclinação por figuras de modalidades desportivas que não beneficiam da exposição massiva aos media, que só arrastam a curiosidade das multidões de anos a anos, por ocasião dos grandes torneios internacionais, e que mesmo assim conquistam um lugar perdurável na memória de um largo espectro de jornalistas, técnicos e adeptos do desporto.

Como entender, pois, um desfecho tão paradoxal?

\section{II}

Uma interpretação não trivial remete- nos para outra questão: qual é a essência do "acto desportivo"? Qual o motivo que incita o homem à proeza atlética e, de certa maneira, imprime no desporto um significado que repercute no imaginário dos povos?

As teorias clássicas do jogo atacaram este problema segundo diversas perspectivas. Alguns autores pretenderam ver, no acto desportivo, a comprovação da teoria do excesso de energia, enquanto outros, instalados em posições pragmatistas, se inclinaram para a teoria do exercício preparatório, associando o desporto, pelo menos nas suas manifestações mais

206 arcaicas, à preparação militar e à aquisição e aperfeiçoamento das técnicas de caça e pesca. Trata-se de visões ao mesmo tempo ingénuas e parciais porque, tal como a investigação o tem demonstrado nas diversas áreas de iniciativa científica aplicada ao desporto - psicologia, sociologia, antropologia, ciências biológicas - este é um fenómeno multidimensional tanto nos mecanismos que solicita como nos significados que reveste enquanto domínio de experiência subjectiva. Não é redutível, portanto, 
a um quadro de explicação singular, mesmo que erigido sobre uma teoria sedutora e cientificamente robusta, de acordo com o paradigma monodisciplinar.

A falência das teorias de jogo na elucidação da essência do acto desportivo - e, em particular, nos seus planos axiológico e motivacional resulta precisamente dessa natureza complexa que não nos autoriza a entender o desporto como sucedâneo directo do jogo através de uma simples mudança de grau. Embora em toda a experiência desportiva persistam elementos residuais do fenómeno lúdico - e isso é inquestionável, pelo menos no plano formal - o desporto contém elementos distintivos originais e outros que, não o sendo de todo, revestem porém intensidade e articulação específicas.

Nos estudantes de Educação Física e Desporto, frequentemente aturdidos com a copiosa produção dos diversos discursos científicos, procuramos estimular um olhar crítico, integrador, do fenómeno desportivo, a partir de três díades fundamentais: naturalismo-racionalismo, regra-transgressão, hedonismo-ascetismo. Dois outros elementos se acrescentam como matéria de reflexão, atravessando o debate científico e filosófico: a superação e o excesso.

A importância do excesso, identificador por excelência do desporto, é tal que Pierre de Coubertin não se sentiu constrangido a esconder o pensamento atrás de conceitos elípticos ou artificiosos. Desporto, como o definiu na sua "Pedagogia do Desporto", é toda a forma de exercício físico desprovida de interesse material - a definição é datada, como sabemos - que visa a superação das capacidades humanas, «se necessário com risco da própria vida.»

Este risco, inerente ao desafio, à proeza, é uma aposta assumida pelo indivíduo na esfera exclusiva da sua consciência. É um acto livre, eventualmente favorecido por uma constituição biopsíquica e por estímulos oriundos do contexto sociocultural, mas sempre uma manifestação individual da vontade.

As mais antigas referências escritas a proezas atléticas são porventura as contidas na llíada e na Odisseia. Comentários, descrições, episódios em que a individualidade dos protagonistas é recortada nos seus múltiplos detalhes. Assim acontece no episódio da corrida de carros disputada durante os jogos em honra de Pátroclo (llíada, 
canto XXIII), precedida da apresentação algo minuciosa dos concorrentes: Emelo, filho de Admeto; o robusto Diomedes, filho de Tideu; o louro Menelau, nascido de Zeus; Antíloco, filho admirável do altivo rei Nestor... O acto desportivo aparece, na tradição homérica, como um sinal da identidade dos heróis - de cada herói em particular: «Quando os cavalos davam a volta na direcção do mar, então aparecia o valor de cada um» (llíoda, ibidem). O desporto e a proeza que o concretiza possuem, assim, um intérprete, um rosto e um nome desde a Antiguidade.

III

O olimpismo moderno tem uma larga responsabilidade na preservação do indivíduo como elemento central, e maior, do acto desportivo. O facto é tanto mais significativo quanto mais desfavorável se apresentava o contexto social e cultural em que o movimento olímpico renasceu, na transição do século XIX para o século XX. Com efeito, o desporto contemporâneo fundou raízes nos jogos de equipa, uma prática quase inexistente no longo transcurso da história. António José SaraivaO, numa das suas últimas obras, sublinhou esta característica originária do movimento pedagógico inglês do século XIX, bem ilustrada em obras literárias da época, como Tom Brown's Schooldaysi²), onde se

\footnotetext{
(ם) «O desporto teve sempre uma grande importância na vida colectiva das cidades e mobilizou multidões e rios de dinheiro. Há desportos que são, na realidade, espectáculos para multidões em que os figurantes estão destinados a morrer às mãos uns dos outros, como os combates de gladiadores. Na Grécia antiga, os Jogos Olímpicos tinham um papel político importante no conjunto dos estados concorrentes. Mas esses jogos eram concursos individuais. Modernamente, o desporto sofreu uma mutação: apareceram os jogos entre equipas, como o futebol, que acrescentou ao espectáculo desportivo uma qualidade teatral: o suspense. Neste tipo de desporto, os agentes em competição são grupos que têm de responder colectivamente a situações imprevistas, e o desfecho é incerto até ao fim.» António José Saraiva, 0 Queéa Cultura?, Lisboa: Difusão Cultural, I 993.

${ }^{(2) \ll ' H o l d ~ t h e ~ p u n t-a b o u t ! ' ~ T o ~ t h e ~ g o a l s ! ' ~ a r e ~ t h e ~ c r i e s, ~ a n d ~ a l l ~ s t r a y ~ b a l i s ~ a r e ~ i m p o u n d e d ~}$ by the authorities; and the whole mass of boys moves up towards the two goals, dividing as they go into three bodies. That little band on the left, consisting of from fifteen to twenty boys, Tom amongst them, who are making for the goal under the School-house wall, are the School-house boys who are not to play up, and hâve to stay in goal. The larger body moving to the island goal are the School boys in like predicament. The great mass in the middle are
} 
descreve, de forma pitoresca, o espírito e o ambiente que presidiam à formação desportiva dos jovens nas public schools britânicas. Esse espírito foi, depois, trasladado a todo o Império, na prática social dos funcionários da administração - os civil servants - e na preparação militar dos soldados.

Na Alemanha, onde o movimento ginástico, o Turnen, responde aos apelos nacionalistas de Fichte através das suas sociedades de inspiração patriótica, o desporto reveste, de ponto de vista da técnica de execução dos movimentos, um carácter individual, predeterminado e invariável, assente no drill. Porém, a concepção doutrinária que o informa inculcaIhe também uma configuração de prática de massa, onde o indivíduo é uma unidade que só tem existência na medida em que serve um sistema - um sistema de gestos, de exercícios, onde a dissonância, o rasgo, a interpretação pessoal não têm lugar nem sentido. No Turnen, ao contrário do instinto lúdico e da atitude hedonista presentes nos jogos desportivos ingleses, o atleta é peça de um projecto, de uma encenação que tem por finalidade produzir um efeito emocional no espectador(3).

Trata-se, pois, de uma ocorrência aparentemente paradoxal, esta irrupção do desporto contemporâneo fundada em duas mensagens contrárias, se não mesmo contraditórias.

Por um lado, a exaltação das massas, dos movimentos colectivos, directamente inspiradas nos nacionalismos emergentes, nos projectos coloniais e nas visões autoritárias de Estado, reunindo assim, num

the players- up, both sides mingled together; they are hanging their jackets, and all who mean real work, their hats, waistcoats, neck-handkerchiefs, and braces, on the railings round the small trees; and there they go by twos and threes up to their respective grounds.» Thomas Hughes, Tom Brown's School Days, Oxford: Oxford University Press, 1989.

(3) Correndo embora o risco de estabelecer uma identidade linear a partir de duas configurações semelhantes, é difícil evitar a analogia entre os festivais do Turnen da primeira metade do século XIX e as grandes paradas, gímnicas e militares, organizadas pelo III Reich. De resto, a obra da "cineasta do regime", Leni Riefenstahl, tem os seus momentos mais altos quer no registo da grande celebração do Partido Nacional - Socialista, em Nuremberga (0 Triunfo da Vontade) quer nos documentários em que fixou os arquétipos da beleza corporal ariana e germânica entregues a exercícios de ginástica de grupo, inspirados na doutrina, na técnica e na estética dos discípulos de Jahn. A semelhança seria apenas formal e acidental ou devemos, pelo contrário, ver aí um fio condutor, ao mesmo tempo ideológico e cultural, que partilha do pensamento alemão e, designadamente, das concepções dos filósofos trágicos e da "filosofia da vontade"? 
mesmo corpo, configurações desportivas e contextos políticos e sociais tão diferenciadas como os da Europa Central, da Grã-Bretanha e dos países germânicos.

E, por outro, um projecto de revivescência dos ideais da Grécia Antiga, celebrando o atleta individual e individuado, cultor da proeza, predestinado pela Natureza (ou pelos deuses?) mas disciplinado por uma vontade e um sistema de treino que são condições necessárias ao desígnio de superação: Citius, Altius, FortiusÁ4) É neste desígnio de superação que radica um elemento fundamental da prática dos desportos individuais: o record. A etimologia é, aqui, um argumento categórico: record, registo; e, por extensão, memória. É essa "memória", desde muito cedo organizada nos anais das primeiras federações desportivas, que viabiliza um dos traços mais conspícuos do desporto contemporâneo: uma iconografia própria.

Embora Pierre de Coubertin não oculte a sua admiração pela pedagogia desportiva dos colégios ingleses, a sua formação cultural e académica segue a tradição aristocrática francesa. É humanística, devotada ao estudo das obras e dos valores greco-latinos, tal como a da maioria dos seus companheiros de empresa. Não foi por isso acidental que Coubertin tenha escolhido a Sorbonne para palco da proclamação do reatamento dos Jogos nem que as suas incursões poéticas, dentro da temática olímpica, tenham uma inspiração explícita em Pindaro.

\section{IV}

Podemos, hoje, afirmar que os Jogos Olímpicos retomaram o ideal clássico, quando a proeza atlética tinha um rosto e um nome, era cantada pelos poetas e alçada pelos mortais à natureza dos actos divinos. Como sistema institucionalizado à escala planetária, supranacional e

(4) São por vezes surpreendentes, nos textos dos Antigos, referências à preparação atlética que revestem validade actual. «Não é possível que um homem seja hábil em todos os exercícios,» declara Epeu, antes de iniciar o combate de pugilato com Euríalo (llíada, canto XIII). Como sabemos, os primeiros jogos Olímpicos modernos tiveram uma significativa representação de atletas que participaram em competições de várias modalidades. Em breve, porém, a especialização impôs-se ao ecletismo, tal como o treino metódico à prática diletante. 
congregador de interesses económicos gigantescos, a entidade que o dirige, o Comité Olímpico Internacional, e sua nomenklatura são, de certo, merecedores de críticas e suspeitas, algumas das quais ainda recentemente se mostraram fundadas em casos de suborno e tráfico de influências. Não obstante, o seu papel na preservação do valor do atleta enquanto indivíduo, enquanto ser singular, e não apenas uma peça integrada num todo, a equipa, preparada segundo uma lógica de produção a que não são estranhos nem o taylorismo industrial nem o "espírito de corpo" da disciplina militar, representa um contributo decisivo para a preservação dos valores mais primitivos e genuínos do acto desportivo - desafio, risco, superação e excesso - num exercício constante de medida em referência ao mundo físico, a si mesmo e ao Outro.

Estes são os elementos primais do agonismo, de certo retidos na espécie por terem representado vantagens selectivas em alguma fase da sua evolução, que o olimpismo exalta e mobiliza nas suas mais altas expressões. Esse é um tributo que a Humanidade tem de reconhecer e gratificar. 